\title{
USING E-PARTICIPATION FOR MISSION STATEMENT DEVELOPMENT: PROMISES AND CHALLENGES
}

\author{
Jonas Fegert, Carolin Stein, Christian Peukert and Christof Weinhardt \\ Karlsruhe Institute of Technology, Institute of Information Systems and Marketing, \\ Kaiserstr. 89, 76133 Karlsruhe, Germany
}

\begin{abstract}
Mission statements are documents that summarize an organization's core values and strategies and are used to motivate employees by creating a common understanding among them. However, studies have shown that employees often seek more involvement in the development of mission statements in their organizations. Digitization pushes the implementation of new information and communication technology in the workplace. Therefore, we argue for the potential of using e-participation for the creation of a mission statement. With this paper, we contribute to digital government research by presenting a nominal group process consisting of eight activities, for the deployment of e-participation for the purpose of mission statement development. We evaluate the suggested process using an existing e-participation tool. Our evaluation results reveal challenges of implementing e-participation with the tested tool, especially regarding the usability. Therefore, we provide an overview of specific improvements in the design of e-participation platforms that should be considered in the further development of such platforms.
\end{abstract}

\section{KEYWORDS}

Mission Statement Development, E-Participation, Digital Government, Participatory Design

\section{INTRODUCTION}

For the purpose of defining shared values, mission statements became a trusted instrument for profit- and non-profit organizations worldwide. They are used as a tool to motivate employees (Klemm et al. 1991), involving them in the strategic management of an organization (Campbell and Yeung 1991), and to create a common understanding among them (King 1978). Since the effectiveness of the mission statement is closely related to its content (Blair-Loy et al. 2011; Sattari et al. 2011), research mainly focuses on textual aspects and elements of the mission statement. However, employees seem to value the development process as equally or even more important than the resulting document (Desmidt and Prinzie 2009). Baetz and Bart (1996) show that employees wish to be involved in the development through active discussions and feedback opportunities and appreciate when the process makes an effort in bringing the team together. Similarly, the organization and the mission statement itself may profit from the discussion of potentially conflicting opinions and ambitions (Baetz and Bart 1996). These findings are captured as well by newer research endeavors highlighting the innovative and transformative power of participatory approaches in organizations (Wagenknecht et al. 2017a; b; c) using methods like open innovation (Adamczyk et al. 2012).

E-participation, a form of e-government also known as digital government, established itself as a way to facilitate citizen involvement in "democratic decision-making" (Macintosh 2004, p. 2) by employing information and communication technology (ICT). Cities, municipalities, companies, and research institutions use e-participation to involve stakeholders in certain processes and decisions. By that, they often try to improve the overall acceptance of certain projects. E-participation research proved that certain tools could strengthen the interest in projects and increase the motivation to participate (Fegert et al. 2020).

When temporary lockdowns prevent personal interactions, which we observe globally during the Covid-19 pandemic, involving employees in mission statement development occurs necessarily online - as opposed to conventional participatory settings like workshops. In such times, e-participation offers itself inevitably as a tool for enabling remote collaborative work (United Nations 2020). Due to its deliberative character (Sanford and Rose 2007), e-participation tools promise to introduce an appropriate environment for participatory 
mission statement development outside of the office, making place for online-consultation and transparent decision-making (Macintosh 2004).

In this paper, we present insights from a participatory mission statement creation process that was realized with an e-participation platform. We present a process consisting of eight activities, for the deployment of e-participation for the purpose of mission statement development. Furthermore, our use case, a research institute at which 32 full-time employees used an e-participation tool to create a fitting mission statement, allows us to draw conclusions concerning the general design of e-participation tools for that purpose. An existing e-participation platform was used to evaluate the users' experience in two questionnaires. Thereby, we want to demonstrate the promises and challenges that arise from using e-participation for mission statement development. Through designing, implementing, and evaluating a process for the given use case, we intend to derive first insights potentially leading towards a design theory for mission statement development with e-participation tools.

\section{THEORETICAL FOUNDATION}

\subsection{Mission Statements}

Mission statements are documents summarizing the core values and strategies of an organization (Baetz and Bart 1996). The mission statement is an important factor in the strategic management also due to its visibility and public accessibility (Cochran et al. 2008). Overall, it provides guidance towards the orientation and goals of an organization, bearing the potential to influence its effectiveness (Desmidt and Prinzie 2009). However, the degree to which a positive impact is reached depends on the design, content, and wording of the mission statement. The respective literature suggests that the following aspects should be included in a mission statement: "target customers and markets," "principal products/or services," "specification of geographic domain," "identification of core technologies," "key elements in the companies' philosophy," "identification of the self-concept," and "identification of the [...] desired public image" (Pearce and David 1987, p. 112). With the message often being the center of research, less attention has been paid to the development process of the mission statement. Research has shown that the creation process is valued as more important or equally important as the actual resulting mission statement (Baetz and Bart 1996) and that the process of developing a commonly accepted message is just as vital as the message itself (Cochran et al. 2008). The process is mainly driven by a strategic planning task force or if the group size is too large, by a sub-committee. Baetz and Bart (1996) showed that within processes of mission statement creation, when stakeholders felt isolated and not sufficiently involved, they usually ended up being unsatisfied with the process. Moreover, collecting input from everyone was often named as a reason for satisfaction. These results indicate that the isolated work of a task force might be an outdated concept and that there might be room for improvement. Therefore, we argue that more inclusive development of a mission statement could solve a few of the mentioned problems.

\subsection{E-Participation}

Technological innovations introduced new ways of citizen involvement and gave rise to e-democracy (Leitner 2018). E-participation presents one form of e-democracy, which is defined as the possibility to participate in and influence policy decisions using ICT (Macintosh 2004). Although e-participation makes use of certain ICTs, no pure e-participation technology exists (Sanford and Rose 2007). The authors demonstrate that e-participation "research tends to focus on liberal, collaborative forms of participation [...] rather than [...] more direct form[s] of democracy" (Sanford and Rose, 2007, p. 416) like e-voting. As a result, e-participation produces more participation, but not automatically more democracy and has therefore to be differentiated from e-democracy (Grönlund 2009). This explains why e-participation tools are especially popular in non-democratic states, where e-participation might be used as a token and public relation tool to draw a picture of modernity and democratic participation ( $\AA$ ström et al. 2012). Besides the use for public participation projects, e-participation has already proved its merits for corporate participation (Niemeyer et al. 2016; Wagenknecht et al. 2017b), where it can support idea creation processes. With its specific orientation towards democratic and socially interactive elements, e-participation and its tools go beyond classical 
computer-supported cooperative work. While cooperative work generally refers to the elaboration or revision of artifacts through joint interactions between individuals (Grundin 1994), e-Participation tends to focus on the exchange of opinions and consensus building. Existing frameworks provide guidance for successfully conducting e-participation projects (Niemeyer et al. 2016; Scherer and Wimmer 2011).

\section{METHODOLOGY AND USE CASE}

Schererer and Wimmer (2011) follow a holistic approach to the design of e-participation projects. They thus suggest a reference design framework that consists of the following four phases: Initiation and Design, Preparation, Realization, and Evaluation (Scherer and Wimmer 2011, p. 7). Each phase should be described by recounting the conducted activities, highlighting related literature, and presenting the respective results. The different phases of this framework will be described after a brief introduction of the use case.

The participatory process will be tested within the development of a mission statement for a technology-oriented institute of a large public European university. The institute is headed by a professor and co-led by a team of six postdoctoral researchers, representing different research groups, which consist of several PhD students as well as graduate student researchers and student research assistants. In total, the research group involves 32 full time staff members, including administrational staff members. All team members are well experienced with technology usage since it is an Information Systems institute. The project was conducted over two and a half months, starting in July 2020 and administered by two of the co-authors of this paper.

Initiation and Design: The initiation and design phase resulted in finding a suitable structure and tool for the participatory mission statement development process. A framework for an effective development of a mission statement is given by Cochran et al. (2008). Their four-step process includes an orientation phase, a component analysis, a communication analysis, and an applicability analysis. Facing the problem of missed shared workspace due to the Covid-19 pandemic, the institute started rethinking practices and values (Table 1, Activity 1). Once the institute's leadership team decided to work on a mission statement, following Cochran et al. (2008), the major headlines framing the mission statement were decided on, to provide a guideline for the following participatory process. Based on the set of relevant aspects of mission statements by Pearce and David (1987), the leadership team structured the discussion into four topics (Activity 2): students ("target customers and markets," "services," "specification of geographic domain"), leadership ("identification of self-concept"), team ("identification of self-concept," "philosophy"), public relations (identification of "core technologies" and the "desired public image").

Reflecting the participants' roles is essential for each e-participation project (Kalampokis et al. 2008). It should thus be differentiated between the input provider, the decision makers, the moderator, and the owner of the process. The structure of the institute directly implies a certain role distribution: the process is headed by the professor, implying that strategic process decisions require his approval. The professor is in the position to initialize the process and agree with the institute's team members on the necessary working time required for the participation. The moderating role was split among the postdoctoral researchers to profit from their position and influence on their groups. They were expected to motivate the employees and be a point of contact in case of any concerns. Since the goal of the project is a participatory and democratic process, the input and decision roles belong to all team members equally.

Preparation: The preparation phase mainly included the search for a suitable e-participation platform. The choice was based on a requirement analysis made by the institute leadership team, agreeing on the following essential characteristics: facilitating idea collecting, group discussions, and voting mechanisms. Phang and Kankanhalli (2008) present a three-step procedure to implement e-Participation initiatives that identifies the (1) objectives, (2) techniques and (3) ICT tools which support the techniques and thereby the objectives. The authors suggest a structured participatory technique named 'decision-making supplement', which fits the intentions of the project at hand and is defined by a nominal group process. A nominal group process is a step-by-step process in which suggestions are ranked, and the outcome of one stage works as a recommendation for the following stage (Phang and Kankanhalli 2008). An ICT tool could for example support an idea collection on a predefined topic, which then merges into a discussion of the ideas and underlying concepts to achieve a consensus through a voting mechanism as a final step. We combined those suggestions with some structural ideas on mission statement development made by Cochran et al. (2008; see Table 1). 
Based on the described requirements and activities, we decided to use a tool developed by a European startup, which is used by public institutions, political parties, and international organizations. The choice of the platform was finalized in a meeting with the startup's CEO and several staff members, who guided us through the characteristics of their platform. The platform claimed being able to support mission statement development processes, while the suggested participation modules resembles our requirements. Table 1 shows the implemented modules and techniques a) and b).

Realization: The e-participation project was conducted over a period of eleven weeks, accompanied by three weeks of offline preparations. The realization started with a hybrid offline and online kick-off workshop. In the workshop, which gave an introduction into the e-participation project and the tool, overall, 86 ideas across the four categories were collected (Activity 3) and transferred to the e-participation tool. For several weeks this initial idea collection was discussed online (Activity 4). Following an online voting (Activity 5), the postdoctoral researchers created sixteen mission statement alternatives out of the top voted proposals (Activity 6). For each of the four categories, these differed slightly in wording and phrasing. This was followed by another online voting (Activity 7), which resulted in a finalized version of the mission statement with one statement for each category. The last step of the idea collection process consisted of working out actions for operationalizing the mission statement into the daily business of the institute (Activity 8). This step led to 131 initiatives how the mission statement could be operationalized and used in the future. During the whole participation process, a weekly e-mail newsletter was sent to the participants to motivate and remind them to stay involved and offering them a point of contact in case of problems. Activity six and seven of this process replace the communication analysis suggested by Cochran et al. (2008) though we believe that the suggested democratic process will bring up the most convenient mission statement out of the alternatives.

Table 1. Activities, Expected Outcomes of the Nominal Group Process, and Modules

\begin{tabular}{|c|c|c|}
\hline Activity & Expected Outcome & Module \\
\hline 1. Orientation & Moderators and owners become aware of their role & - \\
\hline 2. Component analysis & Component categories for the idea collection are specified & - \\
\hline 3. Idea collection & Ideas concerning the different topics are collected & Debate $^{\text {a) }}$ \\
\hline 4. Discussion of ideas & General understanding for different ideas is developed & Prioritization ${ }^{b)}$ \\
\hline 5. Vote on ideas & Ideas are prioritized via up- and downvotes & Prioritization ${ }^{b)}$ \\
\hline $\begin{array}{l}\text { 6. Formulation of } \\
\text { mission statement }\end{array}$ & $\begin{array}{l}\text { Different textual mission statement alternatives are } \\
\text { developed by the leadership team }\end{array}$ & - \\
\hline 7. Vote on mission statement & Decision on the mission statement & Prioritization ${ }^{\mathrm{b})}$ \\
\hline $\begin{array}{l}\text { 8. Idea collection on applicability } \\
\text { and operationalization }\end{array}$ & List of ideas for specific application of the mission statement & Debate $^{\text {a) }}$ \\
\hline \multicolumn{3}{|c|}{$\begin{array}{l}\text { Techniques used: a) Proposals are condensed to predefined categories; possibility to up- and downvote or comment } \\
\text { proposals; filtering and tagging of proposals; b) Opportunity to comment and up- or downvote predefined } \\
\text { proposals; new proposals cannot be added; other users' comments can be up- or downvoted. }\end{array}$} \\
\hline
\end{tabular}

Evaluation: The first process evaluation was conducted after Activity 5 and was included as a module in the e-Participation process. As the preliminary analysis of the first questionnaire has to some degree already indicated signs of dissatisfaction among the participants, we decided to examine the attitude towards the overall user experience of the tool in an additional non-obligatory questionnaire. In doing so, we adapted a theoretical model by Naranjo-Zolotov et al. (2019), which evaluated an e-Participation tool relying on the unified theory of acceptance and use of technology (UTAUT) (see Venkatesh et al. 2003). We used seven-point Likert scales ranging from "strongly disagree" to "strongly agree" to measure the theoretical constructs, followed by three open questions (Table 2). The evaluation results are presented in the results chapter of this paper. 
Table 2. The Two Phases of the e-Participation Evaluation

\begin{tabular}{|c|c|c|}
\hline $\begin{array}{l}\text { Evaluation } \\
\text { Phase }\end{array}$ & Construct (Number of Items) & Statement \\
\hline \multirow[t]{5}{*}{1} & Satisfaction (1) (self-developed) & $\begin{array}{l}\text { I am satisfied with the participation process for the mission } \\
\text { statement. }\end{array}$ \\
\hline & Process Support (1) (self-developed) & $\begin{array}{l}\text { The e-Participation tool has provided useful support for the } \\
\text { participation process. }\end{array}$ \\
\hline & Structure (1) (self-developed) & The e-Participation tool has structured the participation process. \\
\hline & Prioritization Module (1) (self-developed) & $\begin{array}{l}\text { The prioritization module allowed me to clarify my weighting of } \\
\text { the subjects. }\end{array}$ \\
\hline & Debate Module (1) (self-developed) & The debating module allowed me to formulate new ideas. \\
\hline \multirow[t]{5}{*}{2} & $\begin{array}{l}\text { Performance expectancy (3), Effort } \\
\text { expectancy (4), Social Influence (3), } \\
\text { Facilitating conditions (3), Intention to use } \\
\text { (3), Competence (3); Meaning (3); Impact } \\
\text { (3); Self-Determination (3), Intention to } \\
\text { recommend }\end{array}$ & See Naranjo-Zolotov et al. (2019) \\
\hline & OQ1: Open Questions on the Participation & Which parts of the participation process are important to you?; \\
\hline & Process (self-developed) & How do you think an optimal participation process looks like? \\
\hline & $\begin{array}{l}\text { OQ2: Open Questions on Features (self- } \\
\text { developed) }\end{array}$ & $\begin{array}{l}\text { Which features do you expect an e-participation platform to } \\
\text { have?; Which features did you use or for what reason did you } \\
\text { not use others? }\end{array}$ \\
\hline & $\begin{array}{l}\text { OQ3: Open Questions on Aspects of } \\
\text { Usability (self-developed) }\end{array}$ & $\begin{array}{l}\text { Which aspects of usability are particularly important to you on } \\
\text { an e-Participation platform?; What specific recommendations do } \\
\text { you have for the design of an e-participation platform? }\end{array}$ \\
\hline
\end{tabular}

\section{RESULTS}

With this paper, we aim at revealing promises and challenges of the use of e-participation for mission statement development. Given that we only evaluated the tool and method by means of one organization and a small sample size (first evaluation phase $\mathrm{N}=10$; second evaluation phase $\mathrm{N}=21$ ), we do not strive for generalizability of the evaluation results. However, we believe that the evaluation can identify some trends and thereby provides avenues for further research. Taking the evaluation results into account, we have to keep in mind that the assessment of the usability of a an e-government tool may vary depending on the different stakeholders involved in the implementation of the tool (Axelsson et al. 2013). In particular, stakeholder groups with lower urgency for the introduction of a new tool may be more reluctant to accept these tools, while the beneficiaries tend to be more optimistic and develop higher acceptance intentions.

The first evaluation was conducted during the participation process and gave a rather positive impression although it already has shown mixed results in the sense that it became clear that there was no distinct endorsement for the tool, which became even more visible in the second evaluation phase (Table 3 ). The overall satisfaction with the process was rated above average, given that the middle point of the Likert scale is $4(\mathrm{M}=4.30, \mathrm{SD}=1.19)$. Asking about the specific modules, they seem to have fulfilled their purpose: Participants mostly agreed that they could formulate new ideas $(\mathrm{M}=5.10, \mathrm{SD}=1.37)$ using the module for debate and that they could clarify their weighting of the subjects using the prioritization module $(\mathrm{M}=4.50$, $\mathrm{SD}=1.56)$. Although a majority agreed that the tool was useful to support the process $(\mathrm{M}=4.70, \mathrm{SD}=0.90)$, only some participants believed that the tool is structured logically $(\mathrm{M}=3.60, \mathrm{SD}=1.28)$.

In light of the inconclusive results of the first evaluation, we wanted to get a better understanding of the problems the participants see with the e-participation tool. Therefore, we used the constructs of the UTAUT-model based framework of Naranjo-Zolotov et al. (2019) (Table 2) to evaluate the e-participation platform itself. Due to the sample size, we stick to report descriptive results for the variables of interest, since the sample size requirements for a sound structural equation modelling analysis (in accordance with Naranjo-Zolotov et al. (2019) for testing their theoretical model in our context) are not met. Furthermore, we asked some open questions to get feedback that is specifically tailored on the participation process, the usability of the platform as well as its features, and how those aspects might be improved. When we interpret the duality of the results of the second evaluation, we have to keep the technical proficiency of the participants in 
mind - all are associated with an Information Systems institute. The facilitating conditions like the knowledge and resources necessary to use the tool were evaluated overwhelmingly positive $(\mathrm{M}=6.39, \mathrm{SD}=0.82$; please note: Due to an insufficient Cronbach's alpha value (0.64), the item "the platform is compatible with other technologies I use" was removed before aggregating the single item's values to one measure; after removing the item, the construct's Cronbach's alpha value (0.77) met the commonly applied threshold value of .7). The effort expectancy $(\mathrm{M}=5.11, \mathrm{SD}=1.45)$, which captures the ease for the users in learning and understanding how to use and interact with the system, was evaluated positively as well. Furthermore, the users were confident about their abilities and skills to use the e-participation platform, shown by the positive competence outcome $(\mathrm{M}=5.70, \mathrm{SD}=1.16)$. Only slightly above average was the self-determination $(\mathrm{M}=4.37, \mathrm{SD}=1.56)$ the users perceived over their platform use. Self-determination measures the autonomy and independence in the usage and since decision-making processes should rely on the freedom of choice, we would have expected a better outcome. Both constructs, meaning $(\mathrm{M}=4.43, \mathrm{SD}=1.53)$ and social influence $(\mathrm{M}=4.00, \mathrm{SD}=1.36)$, revealed more details about the process itself: The participants apparently saw the projects meaningfulness above average. That being said, a social influence outcome on the middle point of the scale showed no clear opinion if the people with an influence on their behavior would like them to use the platform.

In contrast to the prior constructs, the following showed rather negative results: With the performance expectancy $(M=2.77, S D=1.43)$ the usefulness of the tool in daily life, the ability to accomplish things more quickly and the increase of productivity through the tool is measured. The remarkably low results emphasize that the participants did not see the e-participation tool as a valuable addition to their set of online tools. In this regard, it could be argued that a mission statement development process is not an everyday activity and, thus, limitations in the user experience are tolerable. However, in the same vein, the results for the intention to use $(\mathrm{M}=2.19, \mathrm{SD}=1.11)$ indicate serious concerns. The results revealed hesitancy towards using the e-participation platform besides the presented use case. A below average impact result $(\mathrm{M}=3.44, \mathrm{SD}=1.26)$ showed, that the participants did not see the platforms as a strong means to influence what happens in their community. However, it has to be stated, that interpreting this result is complex, since it could be seen positively that in a process that has been envisioned as democratic, the participants have not overestimated the personal impact. Since there is overall no convincing satisfaction with the used e-participation platform, it does not surprise, that the value for intention to recommend the tool to others is rather low $(\mathrm{M}=3.62, \mathrm{SD}=1.94)$.

Table 3. Descriptive Statistics

\begin{tabular}{lcccc}
\hline Construct & Mean & Median & Standard Deviation & Cronbach's Alpha \\
\hline Satisfaction $(\mathrm{N}=10)$ & 4.30 & 4.50 & 1.10 & - \\
Process Support $(\mathrm{N}=10)$ & 4.70 & 5.00 & 0.90 & - \\
Structure $(\mathrm{N}=10)$ & 3.60 & 3.00 & 1.28 & - \\
Prioritization Module $(\mathrm{N}=10)$ & 5.10 & 5.00 & 1.37 & - \\
Debate Module $(\mathrm{N}=10)$ & 4.50 & 5.00 & 1.56 & 0.89 \\
Performance expectancy (N=21) & 2.77 & 2.33 & 1.43 & 0.86 \\
Effort expectancy (N=21) & 5.11 & 5.00 & 1.45 & 0.86 \\
Social Influence (N=21) & 4.00 & 4.00 & 1.36 & 0.77 \\
Facilitating conditions (N=21) & 6.39 & 6.50 & 0.82 & 0.86 \\
& & & & 0.94 \\
Intention to use (N=21) & 2.19 & 2.00 & 1.11 & 0.93 \\
Competence (N=21) & 5.70 & 5.66 & 1.16 & 0.90 \\
Meaning (N=21) & 4.43 & 4.66 & 1.53 & 0.90 \\
Impact $(\mathrm{N}=21)$ & 3.44 & 3.33 & 1.26 & 0.97 \\
Self-Determination $(\mathrm{N}=21)$ & 4.37 & 4.00 & 1.56 & 1.94 \\
Intention to recommend (N=21) & 3.62 & 3.33 & & third item dropped) \\
\hline
\end{tabular}

For evaluating the open questions, we followed the qualitative research approach of a structured content analysis (Gläser and Laudel 2010). We sorted the answers in three categories:

Participation Process: The responses to the open questions (OQ1) on the participation process showed that the participants valued the general participative character of the process as well as implementing it with the help of an e-participation tool, since the use of an online tool was not questioned by the participants. $20.69 \%$ of the participants mentioned the online voting positively, $17.24 \%$ the online debates, while only $6.90 \%$ mentioned explicitly that they liked the possibility to comment. Some participants (13.79\%) positively mentioned the collaborative teamwork. However, others stated explicitly aspects of the offline workshop 
(13.79\%) and that they liked the combination of online and offline participation (10.34\%) and thereby showing, that some respondents truly valued the offline components of the presented participatory process and that they partly missed personal interactions. In contrast, $13.79 \%$ appreciated the anonymity of the e-participation process and saw it as strength for inner-organizational participation. Only 3.44\% of the contributions highlighted the moderators' role.

Features: Regarding desired features (OQ2) of an e-participation platform supporting a mission statement development the user showed interest in the following functionalities: voting (30.95\%), having surveys (16.67\%), discussion forums (11.90\%), commenting $(9.53 \%)$, submitting own contributions $(7.14 \%)$, and text editing (7.14\%). Other desired aspects were personalized filters and sorting options (7.14\%), better visualization features to illustrate statistics and user behavior on the platform $(4.76 \%)$, process tracking $(2.38 \%)$, and more dynamic moderation features $(2.38 \%)$. Since many of those suggestions were not or only partly supported by the used e-participation platform, we do see room for improvement.

The participants stated important reasons for the hesitancy towards commenting and submitting own contributions, such as doubting the influence of the individual participation, being demoralized by a lack of feedback from other users and fearing a lack of anonymity. In terms of the intrinsic motivation to participate, having no strong opinion on some topics or feeling that there is already sufficient representation of own opinions also led towards not participating.

Usability: Using UTAUT-based constructs to evaluate the tool, we already gave a broader impression on the tool's usability. With the open questions on the usability (OQ3), we therefore aimed at identifying requirements for an e-participation platform for mission statement development. The participants value simplicity $(19.44 \%)$, a clear structure $(16.67 \%)$, interactivity $(13.89 \%)$, and intuitiveness $(11.11 \%)$. Other minor aspects, which each account for $8.3 \%$ of the contributions are transparency, efficacy, and the possibility to participate quickly. Specific suggestions for a better e-participation design addressed mostly a lack of transparent navigation and aimed for a flatter and clearer website hierarchy. Further thought-provoking suggestions were: using aspects of gamification for better user involvement, using icons to make the functions of certain modules directly visible, better tagging features, or even automated clustering of ideas, developing an application for use the e-participation platform more properly on mobile devices, and possibilities to switch between anonymous and non-anonymous user interaction.

\section{DICUSSION, FUTURE RESEARCH, AND CONCLUSION}

Based on the general trend towards digitization of the workplace - especially sparked by the Covid-19 pandemic - we argued that there is a strong case for using e-participation for mission statement development. Within this paper, we demonstrated promises and challenges of using e-participation for mission statement development and our contribution lies in presenting a nominal group process, consisting of eight activities, for their deployment. In our evaluation, we investigated the acceptance of the process and assessed the ICT tool in terms of its features and usability. The small study, which consisted two evaluation phases, showed that there is an interest in using e-participation platforms for this purpose, but the challenge seems to lie in finding the right tools or respectively in refining the existing ones. The evaluation results allowed us to draw first conclusions about the design and implementation of a mission statement process with e-participation. The responses to the initial questionnaire and the open questions showed that the suggested modules (debate and prioritization) were accepted and supported by most participants. We could verify the results of mission statement research (Desmidt and Prinzie 2009) emphasizing that participants value opportunities to participate. Especially voting mechanism seemed to be an attractive feature of e-participation. The respondents also liked more time-consuming activities such as discussions, text editing, or commenting. Therefore, we do not see any need to adapt the suggested nominal group process and do see possibilities for other organizations to reuse it. The users made us aware of the merits of hybrid formats, which connect of- and online activities, since both elements seem important in order to satisfy various stakeholders and create a certain team spirit.

Moreover, the results of the evaluation showed, that the used tool overall did not satisfy the participants. Although users were convinced that they had the necessary resources, abilities, and skills to use the tool, they had a low intention to use and recommend the system. Future efforts to develop or select an appropriate tool for supporting a participative online mission statement process should therefore strongly focus on the usability aspects suggested in our result section, where we showed that tools should be simple and should follow a clear 
structure, which allows fast and intuitive navigation. State-of-the-art possibilities for a more entertaining user experience and better user interaction should be integrated to provide incentives for using the platform.

In this paper, we made the case for the combination of mission statement development with e-participation. Since the used and tested e-participation tools did not met the requirements, for future research, it would be interesting to investigate how other platforms master the described process. Although we primarily focused on mission statement development, we see further potential to use the presented process for other e-participation initiatives which aim for the same project objective namely a decision making supplement. We believe that combining e-participation with mission statement development would be an exciting artifact to be developed within a design science research project (Hevner et al. 2004). Thereby, meta-requirements, design principles and a design theory for an e-participation tool for mission statement creation could be investigated. Addressing the named challenges and aiming to reach the promises in future research, we are interested to see, how our nominal group process for participatory mission statement development will be adopted and refined.

\section{REFERENCES}

Adamczyk, S. et al, 2012. Innovation Contests: A Review, Classification and Outlook. Creativity and Innovation Management, Vol. 21, No. 4, pp. 335-360.

Åström, J. et al, 2012. Understanding the Rise of E-Participation in Non-Democracies: Domestic and International Factors. Government Information Quartlerly, Vol. 29, No. 2, pp. 142-150.

Axelsson, K. et al, 2013. Public E-Services for Agency Efficiency and Citizen Benefit - Findings from a Stakeholder Centered Analysis. Government Information Quarterly, Vol. 30, No. 1, pp. 10-22.

Baetz, M. C. and Bart C. K., 1996. Developing mission statements which work. Long Range Planning, Vol. 29, No. 4, pp. 526-533.

Blair-Loy, M. et al, 2011. Exploring the Relationship between Mission Statements and Work-Life Practices in Organizations. Organization Studies, Vol. 32, No. 3, pp. 427-450.

Campbell, A. and Yeung, S., 1991. Creating a sense of mission. Long Range Planning, Vol. 24, No. 4, pp. 10-20.

Cochran, D. S. et al, 2008. A Framework for Developing an Effective Mission Statement. Journal of Business Strategies, Vol. 25, No. 2, p. 27.

Desmidt, S. and Prinzie, A. A., 2009. The Effectiveness of Mission Statements: An Explorative Analysis from a Communication Perspective. Academy of Management Proceedings, Vol. 2009, No. 1, pp.1-6.

Fegert, J., et al., 2020. Combining e-Participation with Augmented and Virtual Reality: Insights from a Design Science Research Project. Proceedings of the International Conference on Information Systems (ICIS 2020). Hyderabad, India.

Gläser, J. and Laudel, G., 2010. Experteninterviews und qualitative Inhaltsanalyse: als Instrumente rekonstruierender Untersuchungen. VS Verlag für Sozialwissenschaften, Wiesbaden.

Grudin, J., 1994. Computer-supported cooperative work: history and focus. Computer, Vol. 27. No. 5, pp. 19-26.

Hevner, A. R. et al, 2004. Design Science in Information Systems Research. MIS Quarterly, Vol. 28. No. 1, pp. 75-105.

Grönlund, Å., 2009. ICT Is Not Participation Is Not Democracy - Eparticipation Development Models Revisited. International Conference on Electronic Participation, Linz, Austria, pp. 12-23.

Kalampokis, E. et al, 2008. A Domain Model for EParticipation. Third International Conference on Internet and Web Applications and Services, Athens, Greece, pp. 25-30.

King, W. R., 1978. Strategic Planning and Policy. Van Nostrand Reinhold, New York, USA.

Klemm, M. et al, 1991. Mission Statements: Selling Corporate Values to Employees. Long Range Planning, Vol. 24, No. 3, pp. 73-78.

Leitner, M., 2018. Digitale Bürgerbeteiligung: Forschung und Praxis, Chancen und Herausforderungen der elektronischen Partizipation. Springer-Verlag, Berlin, Deutschland.

Macintosh, A., 2004. Characterizing E-Participation in Policy-Making. Proceedings of the 37th Annual Hawaii International Conference on System Sciences, Washington DC, USA, pp. 1-10.

Naranjo-Zolotov, M. et al, 2019. Citizens' Intention to Use and Recommend e-Participation: Drawing upon UTAUT and Citizen Empowerment. Information Technology \& People, Vol. 32, No. 2, pp. 364-386.

Niemeyer, C. et al, 2016. Participatory Crowdfunding: An approach towards engaging employees and citizens in institutional budgeting decisions. Proceedings of the 49th Annual Hawaii International Conference on System Science, Kauai, Hawaii, pp. 2800-2808.

Pearce, J. A. and David, F., 1987. Corporate Mission Statements: The Bottom Line. Academy of Management Perspectives, Vol. 1, No. 2, pp. 109-115. 
Phang, C. W. and Kankanhalli, A., 2008. A Framework of ICT Exploitation for E-Participation Initiatives. Communications of the ACM, Vol. 51, No. 12, pp. 128-132.

Sanford, C. and Rose, J., 2007. Characterizing eParticipation. International Journal of Information Management, Vol. 27, No. 6, pp. 406-421.

Sattari, S. et al, 2011, How readable are mission statements? An exploratory study. Corporate Communications: An International Journal, Vol. 16, No. 4, pp. 282-292.

Scherer, S. and Wimmer, M. A., 2011. Reference Framework for E-Participation Projects. International Conference on Electronic Participation, Delf, The Netherlands, pp. 145-156.

United Nations, 2020. Embracing Digital Government during the Pandemic and Beyond. Retrieved from https:/www.un.org/development/desa/dpad/publication/un-desa-policy-brief-61-covid-19-embracing-digitalgovernment-during-the-pandemic-and-beyond/.

Venkatesh, V. et al, 2003. User Acceptance of Information Technology: Toward a Unified View. MIS Quarterly, Vol. 27, No. 3, pp. 425-478.

Wagenknecht, T. et al, 2017a. Ideate. Collaborate. Repeat. A Research Agenda for Idea Generation, Collaboration and Evaluation in Open Innovation. 13th International Conference on Wirtschaftsinformatik, St.Gallen, Switzerland, pp. 12-15.

Wagenknecht, T. et al, 2017b. Towards a Design Theory of Computer-Supported Organizational Participation. Journal of Enterprise Information Management, Vol. 30, No. 1, pp. 188-202.

Wagenknecht, T. et al, 2017c. Crowdsourcing in a Public Organization: Transformation and Culture. Americas Conference on Information Systems 2017 Proceedings, Boston, USA, pp. 1-10. 